\title{
CONCEDING IN DISAGREEMENTS DURING SMALL GROUP INTERACTIONS IN \\ ACADEMIC WRITING CLASS
}

\author{
Bal Krishna Sharma
}

\author{
A Scholarly Paper \\ Submitted in Partial Fulfillment of \\ Master of Arts in Second Language Studies
}

Department of Second Language Studies

University of Hawai'i at Mānoa

First Reader: Dr. Gabriele Kasper

Second Reader: Dr. Christina Higgins

Spring, 2011 


\begin{abstract}
Using conversation analysis as a methodological and analytical framework, this study presents a sequential analysis of disagreement episodes in small group interactions in an advanced academic writing class. Closer scrutiny of the sequences reveals that in order to bring disagreements to a close, participants make use of an array of interactional resources to defend and establish their positions as well as to challenge other members' stances. They take cautious steps when they give in to the opponent's stance. From a collection of 48 disagreement episodes, I will explain in detail one disagreement exit pattern- conceding- that occurred most frequently (17 times) in the corpus. Analysis of pre-conceding activities in the disagreement episodes shows that participants deploy three major practices before they close the sequence: making an understanding claim, building a peer alliance and proposing an alternative position. The findings expand our understanding of the intricate maneuvers involved in group works in writing classes.
\end{abstract}

\title{
Introduction
}

Expressing personal attitudes, assessments, and perspectives during interactions with their peers is a common practice for students in university classrooms (Waring, 2001; Stokoe, 2000; Frazier, 2007). Assigning students into groups for discussion or writing has shown positive results in second language writing courses (e.g. Leki, 2001; Warschauer, 2002). Unlike mundane conversations, students interacting in groups in university classrooms have institutional goals of accomplishing the task at hand. In situations like the present one, where students have to discuss academic writing issues (e.g. plagiarism, data commentary, writing a book review, etc.), and collaboratively compose texts to share with other classmates, they frequently have differing 
perspectives that are implicitly or explicitly constructed in their talk. Despite their oppositional stances that become apparent through their disagreements in talk, the interactants have opportunities to display multiple perspectives while completing the task assigned to them. Doing disagreements and coming out of such disagreements is one of such focal phenomenon that becomes apparent in group work interactions. In this paper, I show how the participants come out of disagreements and how that is managed locally by the participants themselves in and through their talk and embodied actions. In classroom contexts, managing exits from disagreements poses a regular interactional problem for students, and microscopic study of sequential details on how members resolve disagreements can provide insights on functioning of standard peer activities in an academic English class.

\section{Group work in writing classes}

The second language writing field today is much influenced by a social-constructivist approach based on writing for academic communities (Warschauer, 2002). Arranging students in pairs (Storch, 2005) and small groups (Leki, 2001; Frazier, 2007), and affording them an opportunity to interact with their peers for discussion and collaborative writing is one major way that helps participants co-construct meaning through their talk and other embodied actions. Such collaborative tasks offer students important opportunities to discuss crucial academic writing issues and co-produce texts that provide ownership and responsibility to the members of the group.

Previous studies on such pair and small group discussions and writing tasks have either focused on the product of writing (e.g. Storch, 2005) or examined the interaction to trace grammatical development through such phenomena as recast and scaffolding by analyzing 
language related episodes (Swain and Lapkin, 1995). Such studies, however, have rarely looked into the interactional details and behavior of the participants that are displayed in interactions. One of the studies that fills this research gap was done by Frazier (2007). He examined how the students in an undergraduate writing class draw upon their interactional resources to co-construct meaning through 'touched-off remembrances' and how the members in interaction orient to the talk with their classmates. He reports that the interaction patterns in the data were similar to story-telling patterns found in mundane conversations and that the students working in small groups were able to make a connection between their talk and broader cultural literacy in their communities. The present study provides another example of micro-analysis of group work interaction in collaborative writing tasks by international graduate students in a university classroom setting. One important difference between Frazier's and my study, however, is that the data for disagreement episodes for this study come from a collection and the participants in interaction are all international students, in contrast to analyses of only two cases in Frazier's study.

\section{Disagreements in interaction}

Previous studies on the topic of disagreement have analyzed how the participants display difference in their opinions and perspectives on topics being talked about in interaction. Research in pragmatics has focused on face and politeness in disagreement discourse. Disagreements have been treated as face threatening acts (FTA) - "activities that by their nature run contrary to the face wants of the addressee and/or the speaker" (Brown \& Levinson, 1987:70). The body of research on disagreement in the tradition of conversation analysis (CA), on the other hand, has used varied terms like 'disagreement' (Mori, 1999) 'argument talk’ (Muntigl \& Turnbull, 1998), 
'conflict talk', 'disputes', and 'oppositional exchanges' (Georgakopoulou, 2001). Georgakopoulou (2001), however, notes that these terms have often been used interchangeably and there are fuzzy boundaries between them. My present research does not aim to address the problem of defining the meta-language and my choice of the term 'disagreement' is based on the sequential organization of the talk locally constructed by the participants in pursuing their oppositional stances in a moment-by-moment basis. Other closely related words like conflict, argument or dispute refer to the same interactional phenomenon unless stated otherwise.

In one of the early studies on this topic, Pomerantz (1984) analyzed the sequential organization of agreements and disagreements in assessment sequences. She distinguished preferred and dispreferred action turn shapes: the former maximizes the salience of the performed action while the latter minimizes it. In the data she analyzed, disagreement was a dispreferred action, and its presence was mitigated through the use of devices such as delays and hedges. Such prefaces sometimes took the form of weak agreements first and then were followed by disagreements later. Her observations can be illustrated in the following examples:

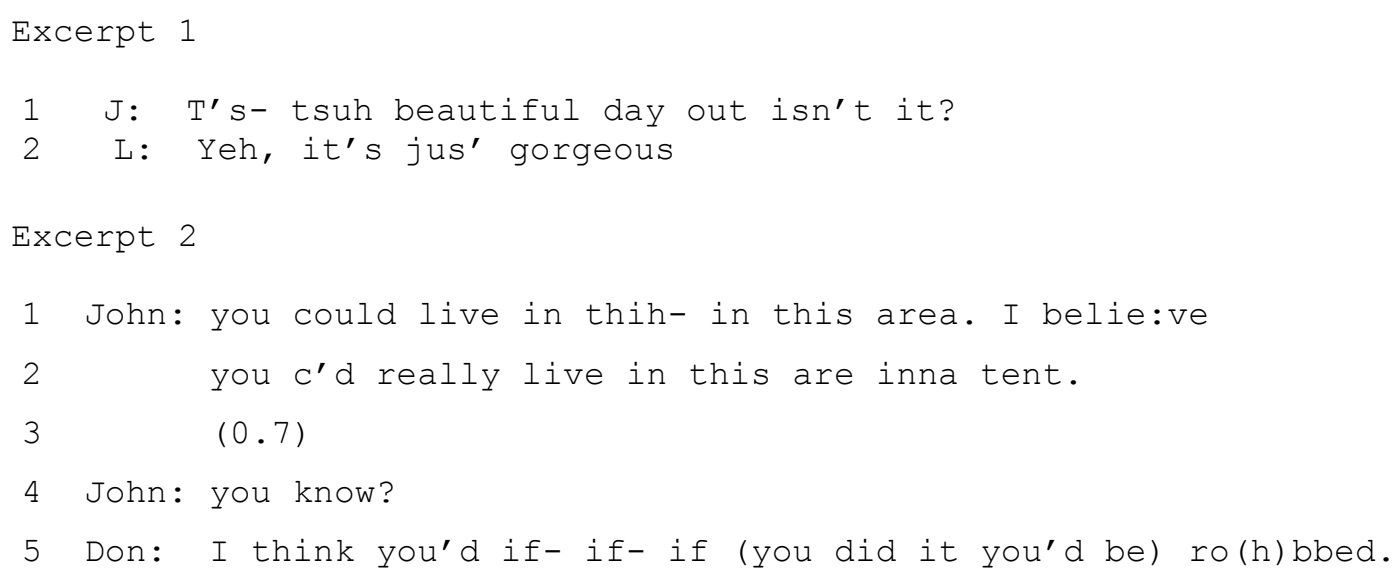

In excerpt 1, in response to J's positive assessment of 'beautiful day', $\mathrm{L}$ offers an agreement promptly with an upgrade, using 'gorgeous' instead of 'beautiful'. Contrarily, in excerpt 2, Don's response for John's proposal is prefaced with 0.7 silence (line 3 ) and mitigating devices, 
e.g. hedge ("I think") and cut-offs (line 5). Disagreement response occurs only after the initial speaker in line 4 requests a response. According to Pomerantz (1984), all these features make disagreement a dispreferred activity.

In line with Pomerantz's research, Mori (1999) studied disagreements in opinionnegotiation sequences in a classroom context focusing on '-demo' and '-kedo' as interactional tokens used by Japanese native speakers and had similar findings: participants in interactions incorporate these "self-qualifications" in order to negotiate their opinions and mitigate their dispreferred responses. She argued that the use of '-demo' and '-kedo' resembled findings in previous studies of the English contrastive marker 'but' as reported in findings by Pomerantz (1984) and Schiffrin (1987). Both Pomerantz (1984) and Mori's (1999) studies show that disagreements are regular phenomena in conversations.

Extending the research context to English as a foreign language (EFL) classroom context, Fujimoto (2010) analyzed peer group discussions in an English communication class in Japan. The following excerpt shows an example of such peer interaction.

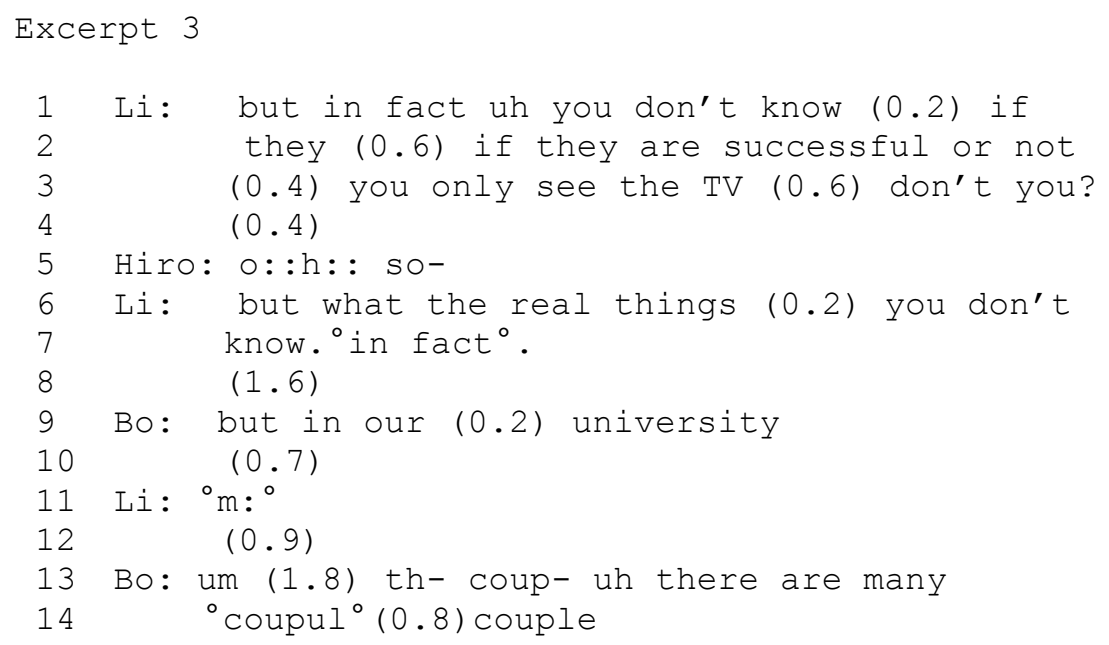

Here the students are discussing their opinions about international marriage in small groups in class. Following Fujimoto, Li makes a direct counter to Hiro's previous assessment that 
international marriage is successful (not included in the excerpt), by beginning with the contrastive marker 'but' and claiming that Hiro's statement comes from television (lines 1-3). She also makes another challenge by stating 'you don't know' without any mitigation (lines 6-7). Another participant Bo again counters Li's claim by indicating that there are some successful couples in their university (lines 9, 13,14). Based on this observation, Fujimoto argues that such disagreements are both expected and preferred in classroom discussions and are a good resource for students to display knowledge and explore the subject matter.

Findings from the above studies show that disagreements are both regular and expected in mundane as well as institutional contexts such as classrooms. These studies, however, did not aim to examine how participants exit from disagreements. What is of particular interest for the present study is an array of post-disagreement activities that the participants engage in to close disagreement episodes. Study of such closings is both important and necessary because interactional exits limit the duration of argumentative exchanges and wedge the intensity of conflict. These exits also prepare the participants to take some further subsequent action related to the task at hand. In this research report, I analyze one particular type of interactional exitconceding- where one or more member(s) of the group give in their position and accept another's.

\section{Participants, data and methods}

The participants in this study were seven international graduate students who were enrolled in a course in academic writing in an English language institute at a North American university. They were students in Public Health, Urban and Regional Planning, Civil Engineering, Botany, and Education, and came from China, Japan, the Phillipines, and Bangladesh. The data for this study 
came from approximately twelve hours of video-recorded student interactions before and during academic writing tasks. These data were collected in five installments spreading throughout the Fall semester of 2009. Each class session lasted for one hour and fifteen minutes. Students worked in two groups to discuss crucial academic writing issues and collaboratively compose texts. Owing to the nature of collaborative writing assignments (see Keys, 1996; Bonito \& Sanders, 2002, for details), writing and discussion tasks are embedded in each other. The candidate episodes for analysis, thus, come from different phases of writing and most interactions are part of the writing task itself.

From the corpus of videotaped peer interactions, I assembled a collection of 48 disagreement episodes. Using standard conventions of CA (ten Have, 2007), I initially transcribed the audio files paying attention to temporal and prosodic features. Subsequently I watched the video to add non-verbal features evident in the participants' interaction with their peers and with artifacts relevant to their activities (e.g. handouts, computer screens, etc.). I did a line by line sequential analysis of the data set, carefully paying attention to those sequential moments where the participants made interactional attempts to proceed from disagreements to exits in a stepwise fashion. I also draw insights from C. Goodwin's (1981) work on how the participants deploy embodied actions and talk together in order to construct and display their stances and positions in interaction. There are 17 disagreement episodes in the collection that end when one or more members of the group give in their position by accepting a position of another party. I have included those excerpts that best illustrate the candidate phenomenon being discussed. It is to be noted that although the students worked in groups, some disagreement sequences take place only between two members. 


\section{Interactional practices of conceding in disagreements}

I am using the term 'conceding' in a sequential sense to refer to an interactional phenomenon terminating a disagreement sequence when one or more members of a group give in and accept the position maintained by the other party. Such an acceptance dismantles the oppositional structure of the interaction and usually marks the termination of a disagreement episode (Vuchinich, 1990). I am using the term interactional practices to include some specific discourse resources and pattern (e.g. verbal exchanges, embodied references, artifacts, etc.) that the participants deploy to defend their own positions and/or to oppose or acknowledge the validity of other members' stance. In what follows, I will first explain three different patterns of conceding although the distinction between them is loose as they share some common interactional properties.

\section{Making understanding claim and conceding}

When group members in the present context differ in their positions in discussions either before or during collaborative writing, one or more members claim understanding, correcting the other member's knowledge or understanding, and the other member(s) consequently brings a change in his/her epistemic stance and accepts the other point of view. This is shown in excerpt 4 . This excerpt comes from a workshop on avoiding plagiarism and is embedded in the collaborative writing activity. The students are paraphrasing a paragraph taken from their textbook chapter. Here, Hasan is providing the text in oral form while Amor is composing it on her computer. The third member, Satoko, is not making any verbal contribution at the moment. Disagreement surfaces when Amor proposes an alternative text to Hasan's text.

Excerpt 4: or you could say 


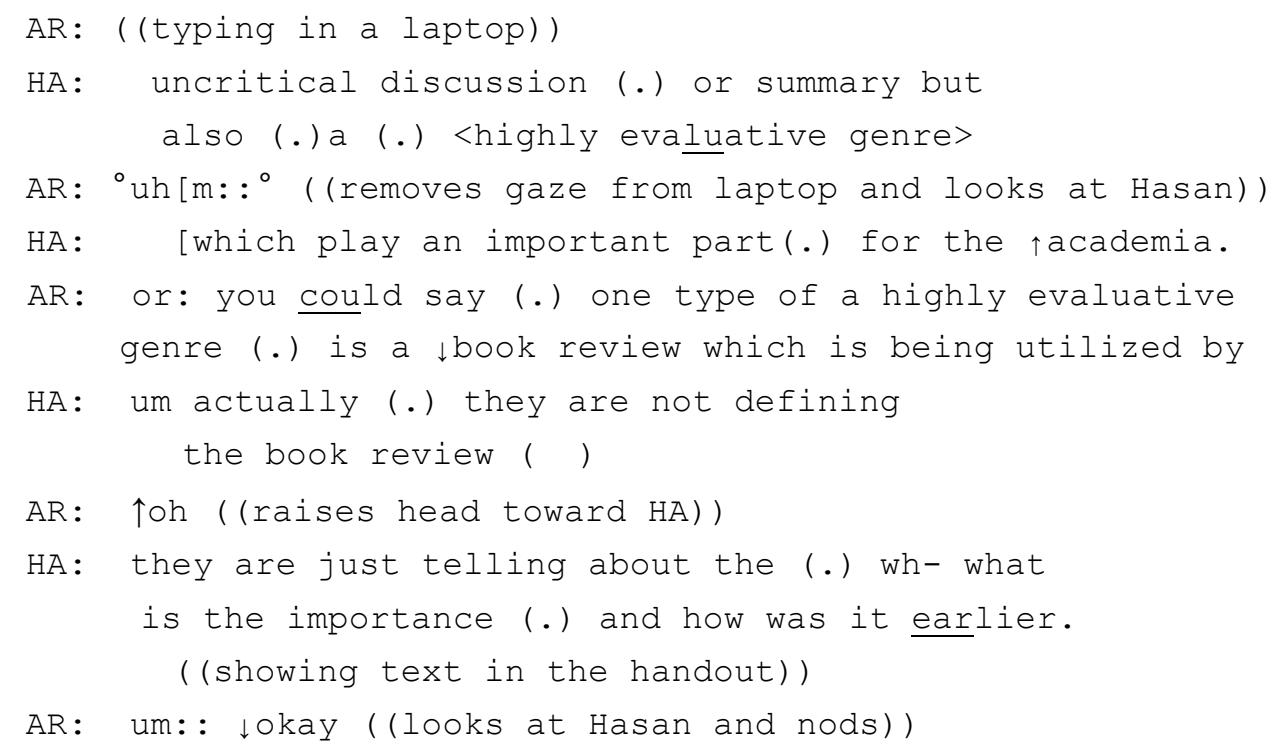

On hearing Hasan's input text 'uncritical discussion or summary but also a highly evaluative genre' (lines 2-3), Amor bids the floor while preparing to disagree using a stretched but relatively quiet hesitation marker (Fujimoto, 2010) 'uhm::' ( line 3). This opportunity, however, is pre-empted when Hasan overlaps with her incipient turn and continues to provide the candidate wording for the text being paraphrased (line 5). Amor, then, disaligns with Hasan by suggesting an alternative text, 'one type of a highly evaluative genre is a book review which is being utilized by' (lines 6-7). Hasan, however, defends his proposal and thus disagrees with Amor. His response turn starts with the delay tokens 'um' and 'actually', signaling his preparation to contradict and provide an alternative for the previous speaker's text. Hasan does not give an account for why he takes his text to be a correct paraphrase, but he constructs Amor's proposed text as a wrong paraphrase of the original text. Hasan shows that he believes that Amor misunderstood the original text, as shown in her paraphrase. He opposes her understanding of the text by referring to evidence in the text. Hasan makes an implicit understanding claim by discursively constructing himself as the 'knower' of the source text's meaning. Amor then immediately acknowledges Hasan’s proposal by using a change-in-epistemic-stance token 
(Heritage, 1984) 'oh' in a rising pitch with a raised head and this marks a receipt of new information in line 10. This sequential moment shows a difference between Hasan's and Amor's interpretation of the meaning of the text. Such a difference in interpreting the text is consequential for losing the position one holds in this context. Hasan continues to make interpretation of the meaning of the text for Amor referring to the original author's voice (lines 11-12).

Goffman's (1981) concept of change in footing provides a useful tool at this point to take account of Hasan's action to bring this disagreement sequence to a close. Footing, following Goffman, refers to the "alignment we take up to ourselves and others present as expressed in the way we manage the production or reception of an utterance" (p. 128). Hasan changes his footing from principal to an animator-from the role of a person whose underlying point of view was expressed to the role of a person who speaks other's thoughts and words as a voice box. It can be argued that this change in footing by referring to the voice of the source text authors is an interactional resource used by one of the disagreeing members to establish his oppositional position in the argument. This change in footing makes Amor finally give up her position and align herself with Hasan using an acknowledgement token 'okay'. It is notable that her acceptance of the opponent's position is prefaced with a hesitant marker 'um::', treating the action as dispreferred (Pomerantz, 1984; Kotthoff, 1993).

Members do not always readily accept other members' positions in disagreement contexts. Before they accept, they may display uncertainty or ask confirmation questions as well as make candidate attempts to account for their differing position before they concede to the other party. Such accounts are useful tools for maintaining positive social relationships as well (Potter, 1996). 
Participants may use task guidelines or invoke the recipient's common sense knowledge in order to establish their position. Excerpt 5, for example, presents a case of conceding with a change in epistemic stance while the participants were working in groups in a workshop on pragmatics of email writing. Each of the four students had a handout which contained the following task: Write an email to the ESL institute Director asking for a leave of absence for one week. Reason: you are going home for your sister's wedding. Ask politely for a reply. Thank the Director in advance for his help. Before they inscribed the text, they decided to discuss the possible email text orally. Disagreement takes place between two members only while the other two members refrain from participation.

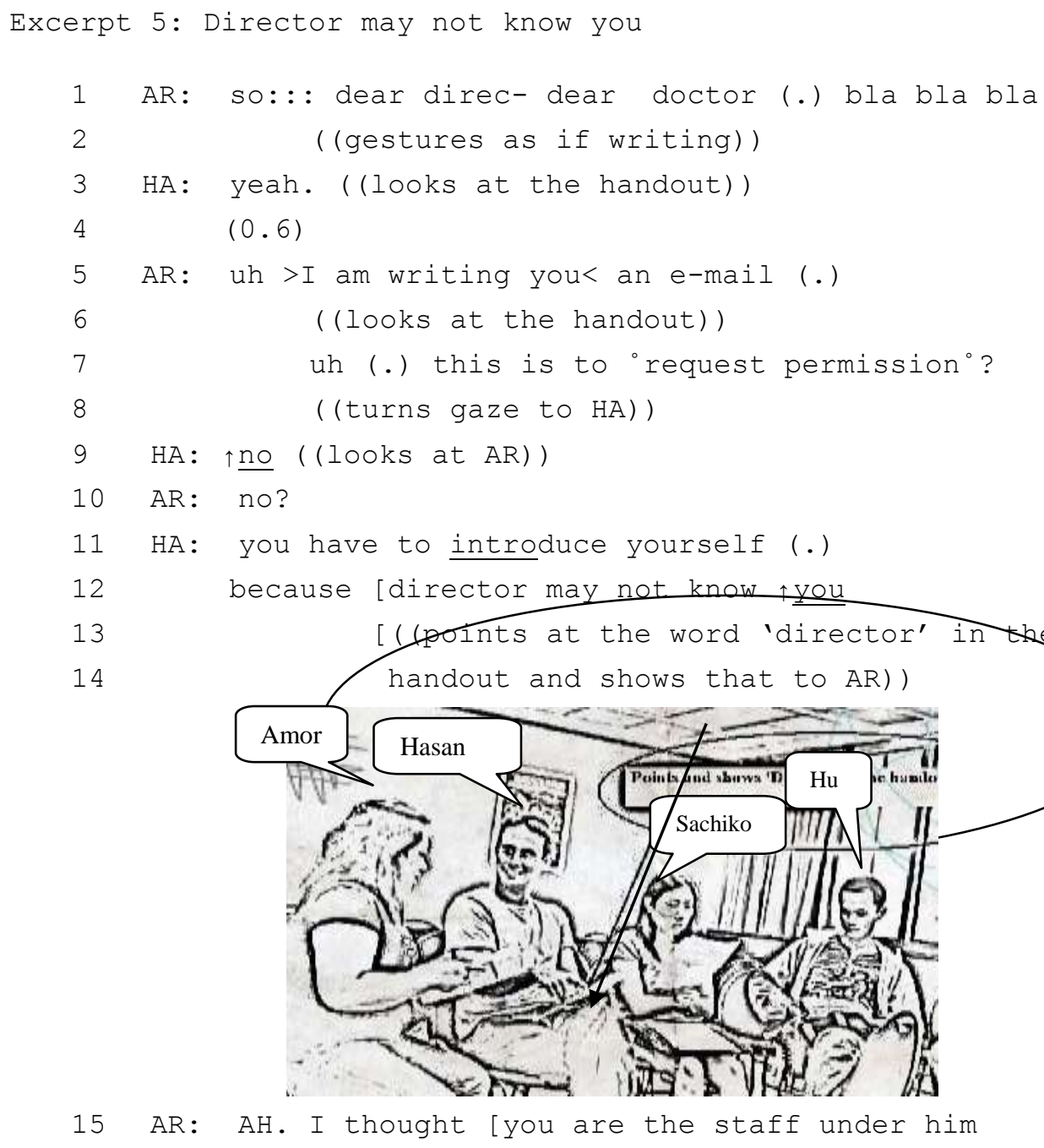

15 AR: AH. I thought [you are the staff under him 


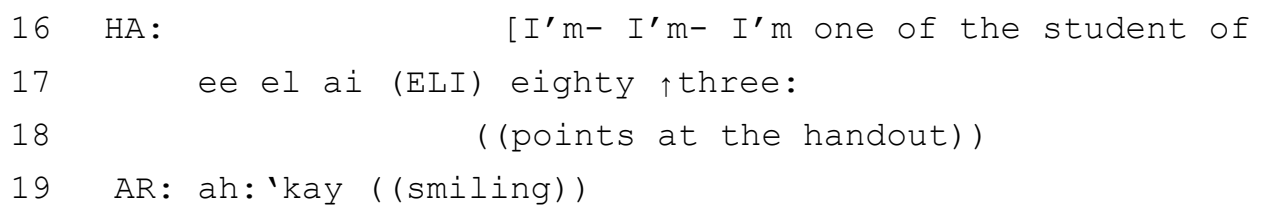

Starting from salutation to the opening sentence, Amor proceeds to orally compose an email to the Director in lines 1 and 2. Hasan recognizes Amor's contribution and turns his gaze from her to the handout, thereby refraining himself from making further contribution. After the lack of further uptake by Hasan (line 4), Amor elaborates the ongoing oral text with some perturbations marked by two micro pauses and two discourse tokens 'uh' (lines 5-7). These perturbations provide a clue that she has trouble to further expand the text. The prosodic features of her final stretch of words 'request permission' (line 7) deserve close inspection because this part is produced with a softened voice that ends with a rising intonation. The question intonation, weakened voice and her simultaneous gaze to her interlocutor indicate that Amor is both displaying her uncertainty as well as seeking confirmation from Hasan by try-marking (Sacks \& Schegloff, 1979) her previous utterance. Her solicited invitation for confirmation is responded by Hasan without prefacing any mitigating device, but with a strong disagreement marked by a high pitch and an emphatic stress on 'no' in line 9. Amor, however, asks another agreement-projected confirmation-seeking question 'no?' (Heritage, 1988) before she offers any elaborate comment on Hasan's response. At this point, it becomes conditionally relevant for Hasan to reconfirm Amor's uncertainty with a more elaborate response. Then he recommends that Amor has to introduce herself in the email before going into its further details, followed by his account of his alternative proposal (lines 11-13). In doing so, Hasan works to invoke the recipient's commonsense knowledge constructing the Director-- person who the e-mail is supposedly being drafted for-- as somebody who does not know the names of all the students in his institution. Therefore, trading on another member's common knowledge is a powerful rhetorical strategy 
through which one can legitimize his/her claims about the appropriateness of the argument (Pomerantz, 1986). In addition, when Hasan utters the word 'Director', he simultaneously makes reference to the handout by pointing out the word 'Director' there. It is notable that in order to establish his position as valid and Amor's proposed email text as incorrect, Hasan claims his knowledge as legitimate by frequently invoking the handout as a more authoritative document, something that provides a set of prescribed guidelines from the more authoritative instructor. Therefore, the knowledge claim is not simply by virtue of the fact that one has authoritative access to a source knowledge that the other does not, but how one understands and interprets the task in situ. Here again, Hasan shifts his footing (Goffman, 1981) making the handout guidelines as the principal. Amor's response to Hasan's account in line 15 cues a conceding of her stance by using a change of state token (Heritage, 1984) followed by an account. Such an account provides a 'moral order' (Goffman, 1981) for Amor to manage her sudden position shift.

Overlapped with Amor's turn in line 16, Hasan does not orient to her utterance but continues to compose the email orally while simultaneously attempting to confirm the validity of his text by referring to the handout. The disagreement sequence does not go too far because Amor in line 19 gives in by displaying a change in her epistemic stance for the second time by issuing the combined receipt tokens 'ah: okay' uttered with a smile. This action shows that she registers as well as accepts the stretch of text proposed by Hasan in the previous turn.

The resources that the participants use to bring this disagreement sequence to a close, however, require some further comments. Amor's try-marked question (line 7) and the subsequent confirmation seeking question (line 10) imply that the position she holds is relatively weaker and is subject to challenge by another group member. The opposing member, Hasan, on the other hand, not only provides an answer to Amor's confirmation-seeking questions, but also 
offers an account for his differing stance. Though the current context of collaborative email composition is different from asymmetrical tutoring context between a peer tutor and a tutee, Hasan's practice is comparable to the advice resistance practice invoking "someone at a higher rank, with greater credibility" (p. 156-57) by a student in Waring's (2005) study. In both the contexts, nevertheless, the authorities being invoked are used as resources by the participants to validate their arguments in order to establish their position, thereby disagreeing with the position another member holds.

\section{Building peer alliance and conceding}

Unlike in the previous excerpts where the non-disputing members participated minimally, members in multiparty interaction can have an opportunity to align to the stance one of the disagreeing parties holds (Kangasharju, 2002). Excerpt 6 comes from another group discussion in the same 'plagiarism workshop' and the students are discussing eleven different 'yes'/'no' prompts regarding whether these are examples of plagiarism in academic writing contexts. The major point of disagreement is between Rohan, and Yuki and $\mathrm{Hu}$ on the point: Is it plagiarism to buy a paper to turn in as your own?.

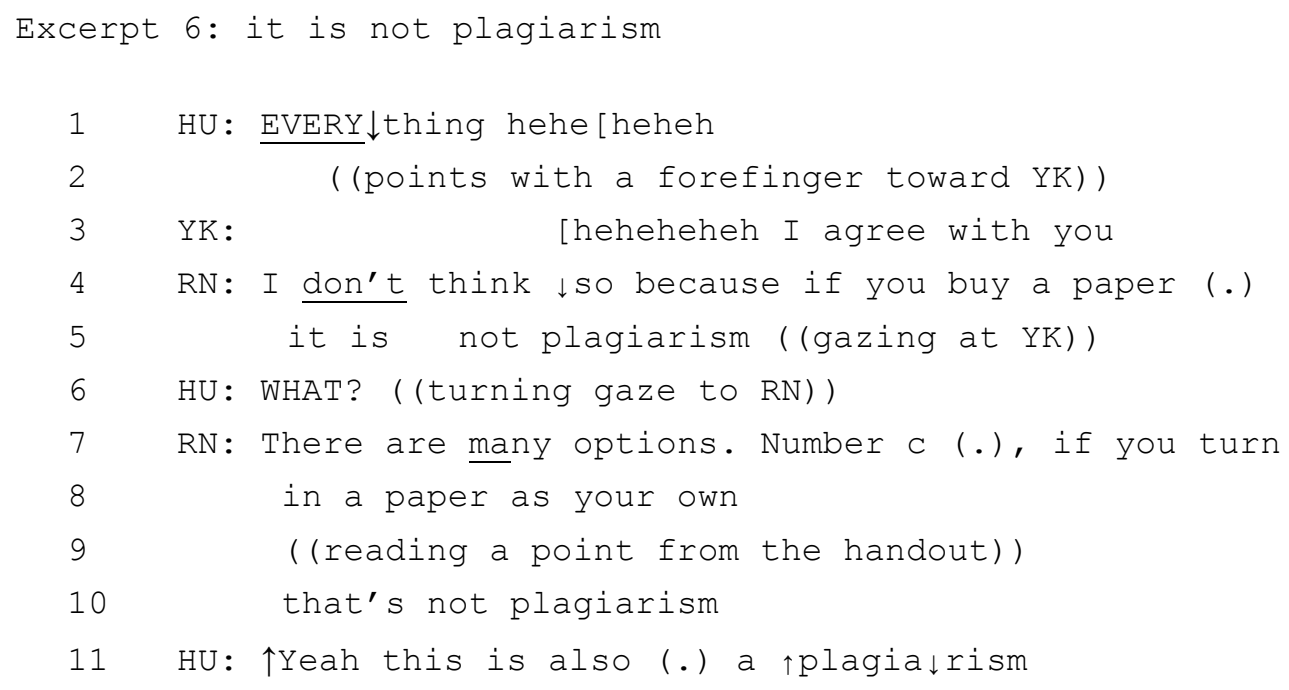




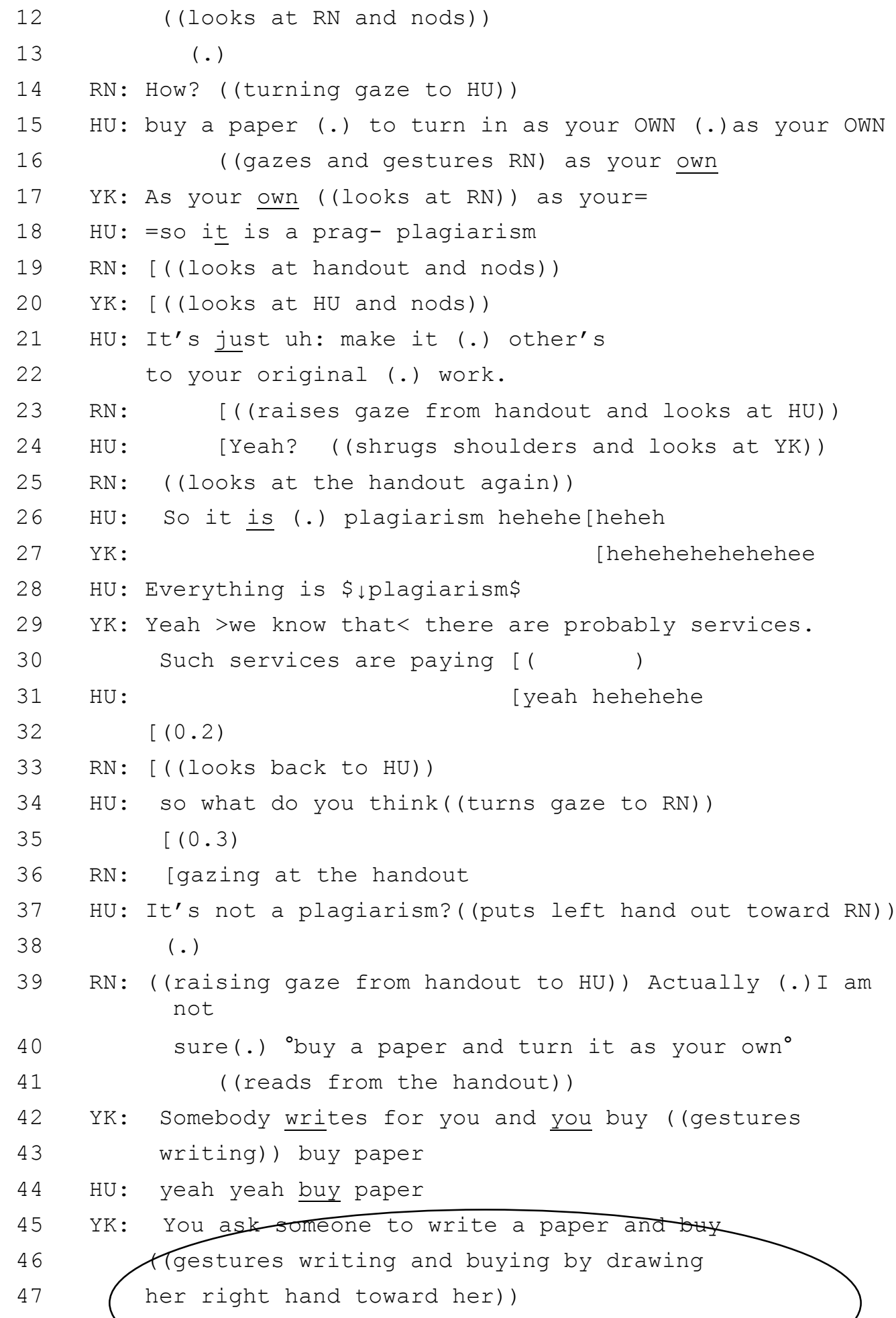




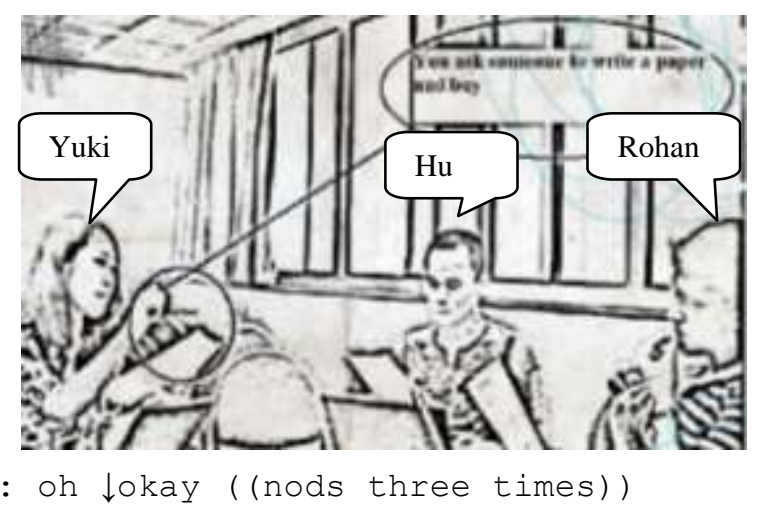

Exchanging mutual gaze and laughter with Yuki, Hu makes a comment formulating an extreme case (Pomerantz, 1986) that 'everything' (all the techniques of citing the source) is an example of plagiarism and invites Yuki to join him with laughter and a pointing gesture towards Yuki (lines 1 and 2). Yuki promptly aligns with Hu with affiliative laughter (Jefferson, 1979) followed by an agreement (line 3). Though this turn with shared laughter potentially prepares these two participants to close the sequence (Holt, 2010), Rohan in line 4 and 5 addresses his gaze to the immediate speaker Yuki and launches his disagreement with a point of contention that buying a paper is not plagiarism. Hu, whose principal position is being contested, throws a question 'what' with a distinct rise in volume and intonation. This 'what' token does more than an initiation of repair (Tagaki, 1999), and thereby constitutes RN's disagreement as unexpected in the first place. Now it is conditionally relevant for Rohan to respond to Hu as well as defend his own position. He reiterates his position 'buying and turning in a paper is not plagiarism' (lines 710) referring to the same sentence from the handout. Here, Rohan and Hu are fundamentally doing categorization work- what counts and what does not count as plagiarism in academic writing. $\mathrm{Hu}$ also issues disagreement with an assessment, repeating his previous position (line 11-12). M. Goodwin (1990) observes that repetition in such sequences may aggravate the disagreement instead of bringing it to a close. This repetition of his stance, however, is subject to explanation when Rohan challenges him again with another question (line 14). 
$\mathrm{Hu}$ and Yuki form a team against Rohan at this point. The collaborative action they are doing is to defend their oppositional stance to Rohan's position. Both try for Rohan's understanding of the meaning of the sentence 'to buy a paper and turn it as your own' by using the words from the handout (lines 14-17). The gaze by Hu and Yuki shows their vocal and nonvocal actions are directed to Rohan. In addition, their repetitions of the phrase 'as your own' several times, with a clearly marked loudness for the word 'own' by Hu, show their attempt to get Rohan to shift his understanding of the meaning of the sentence and legitimize their own understanding. After Yuki echoes Hu's vocal and non-vocal actions, he reinforces their joint position by formulating the upshot from their just-prior talk, prefaced by a latched conclusive "so". At this transition relevance place (Sacks, et al., 1974), Rohan only acknowledges the receipt of the information and looks at the handout but refrains from making further comments (line 19). By looking at $\mathrm{Hu}$ and nodding in response to his repeated categorization of turning in a purchased paper as one's own as an act of plagiarism, Yuki reinforces her position on the matter. This allows Hu to continue his argument. He launches another attempt to make Rohan accept his argument not by repeating the same sentence but by paraphrasing the original text-- 'make it other's to your original work'-- from the handout. In order to validate his argument, he invites confirmation and alignment from Yuki with a question 'yeah?' and indicates his pervading position with an accompanying burst of laughter (lines 26). Yuki promptly aligns with Hu with an affiliative laughter (line 27). Because Rohan has a minimal response and participation and has not yet demonstrably aligned to the opponent's position, Yuki aligns with Hu's repeated stance again (lines 29 and 30) and gives further examples that there are writing services available if one can pay. Hu again aligns with Yuki with laughter. This affiliative laughter is another attempt to 
make Rohan give in to them. Rohan, however, claims no verbal turn as indicated by silence in line 32 , but just directs a gaze to $\mathrm{Hu}$.

When Hu nominates Rohan for the next turn, he asks an open ended question in line 34. This so-prefaced construction connects the preceding talk to the question (Schiffrin, 1987), inviting Rohan to consider the question in light of the prior talk. There is, however, a lack of uptake by Rohan, which is indicated by a silence of 0.3 seconds. When the projected response is not forthcoming, the speaker of the preceding turn has to review what has been problematic in it (Kasper \& Ross, 2007). One of such problems, which also applies to this context, is a potential dispreferred response (Pomerantz, 1984; Gardner, 2004) from the speaker of the second pair part. Davidson (1984) also notes that silence is rejection-implicative in such interactional contexts: when there is a lack of uptake, there can be more of a potential rejection rather than a comprehension problem (p. 127). My data also shares some sequential similarities with findings from Kasper and Ross (2007) from English oral proficiency interviews (OPI) in the Japanese context. In their collection, when the response to the first pair part question was not forthcoming, the interviewers frequently redesigned their questions replacing less common lexical items with more common ones, and those re-worked questions were successful to get an immediate response. In the present context of group discussion, Hu shifts from an open-ended question to a closed-ended question (line 37). This reversed polarity question (Koshik, 2002) projects "yes" as a preferred answer from Rohan and thereby seeks a confirmation to a position $\mathrm{Hu}$ is already holding, thus inviting Rohan to accept the opponent's stance.

Rohan, however, refuses an immediate uptake even after the second question is posed (line 38). Line 39 presents another punchline in the sequence when Rohan displays uncertainty of his position saying 'actually I'm not sure' (lines 39 and 40). By displaying his uncertainty, 
Rohan further downgrades his position from somebody advancing a challenge to one in need of confirmation of his position though it is not made explicit at this moment whether he is revising his previously held position or his understanding of the prompt. A similar interactional practice has been also observed by Waring (2001) in her data from graduate seminar discussions. She refers to this practice as 'asserting vulnerability' where members exercise a backdown tactic to "exit an interactional deadlock created by ungratified disagreement" (p. 42). Such an explicit or implicit downgrading of one's own competence is an indication of submission (Kotthoff, 1993). Rohan designs his turn with several prefacing devices: a lack of uptake, a pause and a hedge. Displaying backdown with uncertainty, thus, is a dispreferred activity at the moment. He then proceeds to silent-read the same sentence from the handout in order to reconfirm his own understanding or stance. Rohan's display of uncertainty is immediately orientated to by Yuki (lines 42,43 ) as an opportunity for her to re-assert her own position. Hu immediately orients to Yuki's interpretation with packaged use of acknowledgement and repetition (line 44). Yuki makes another paraphrase of the original text with accompanying gestures as shown in the picture (lines 45-47). Rohan's packaged use of change of epistemic stance and acknowledgement token 'oh okay', with his gaze directed to Yuki, signals his transition from a state of not-knowing to a state of knowing. It, however, is still not clear whether this change in state marks his shift in understanding of the prompt or a shift in his position of argument. Whatever the reason, this action implies a concession with an acceptance of the opponent's position, bringing this disagreement sequence to an exit. He treats the whole activity as dispreferred by displaying resistance with a lack of uptake followed by an action invoking his uncertainty.

As we have seen in excerpt 6, participants cautiously use several resources to make a stepwise exit from disagreements. The members whose position is finally accepted by the group 
defend their stance by arguing for their position as well as by challenging other members' views on the topic. This analysis also shows how 'convincing' is accomplished interactionally by Yuki and $\mathrm{Hu}$, and how Rohan is doing 'conceding' over many steps. Hu and Yuki do not only challenge Rohan's view, but also paraphrase the task to make him understand its meaning. Such a way of paraphrasing or glossing bears some similarities with the notion of formulation in the conversation analysis literature (e.g. Garfinkel \& Sacks, 1970; Heritage, 1985; Heritate \& Watson, 1979). Though the term has been mainly used to describe the practice of "summarizing, glossing or stating the gist" (Heritage, 1985: 100) of the previous speaker's utterances, the meaning can also be extended to refer to the participants' practices to restate the sentences and/or words from another source (e.g. the handout in this case) or speaker without a substantial change in meaning, in the present context. Formulations are common in institutional interactions, and they are useful tools to enable the "parties to test their positions to move towards the resolution of conflict" (Ariminen, 2005: 95).

Excerpt 7 is another episode from an 'e-mail pragmatics workshop' while the students are collaboratively drafting an e-mail. It presents another case of disagreement where three members (Hu, Rohan and Hasan) form an alliance against another member of the group (Amor). At the moment, they are discussing an appropriate wording for an e-mail text to the Director of a language institute. In this task, the participants are displaying their disagreement while negotiating letter writing regarding whether they need to explicitly mention the reason behind being absent from the school for one week or they just can mention a rather vague 'family or personal' reason. Because they need to construct an e-mail text that is agreeable to all members, some form of consensus is necessary to move on to the next task at hand.

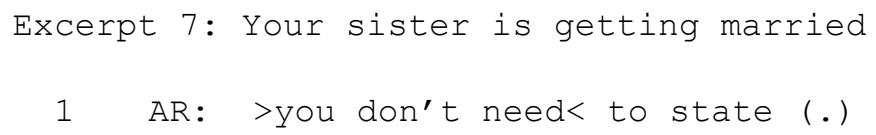




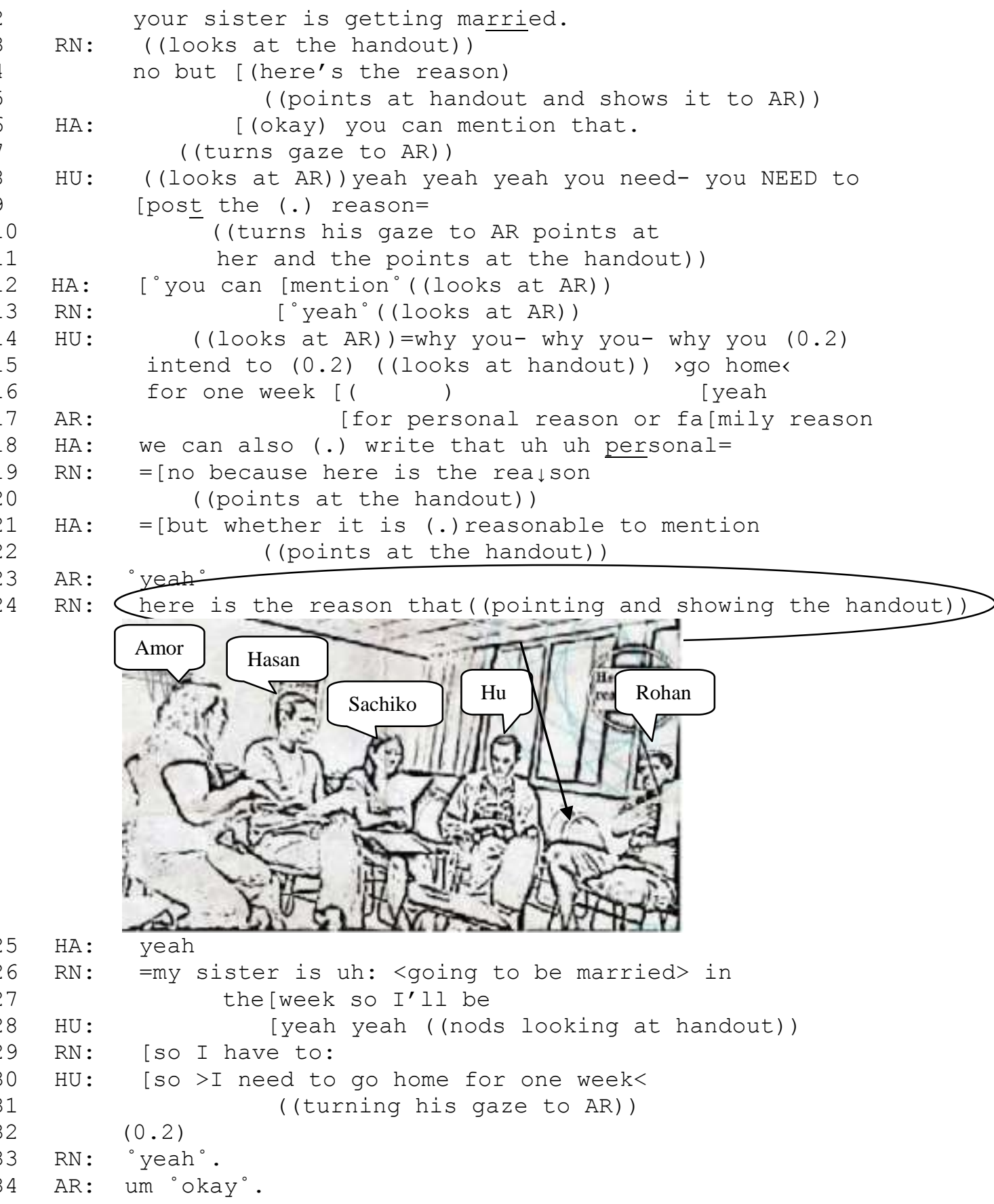

In line 1, Amor claims that they need not mention the specific reason that their sister is getting married. Rohan then does a weak agreement first with 'no' and then launches his disagreement, prefaced with the contrastive marker 'but'. By doing so, he places himself in an opposite stance drawing Amor's attention to the handout guidelines as a point of reference. His opposing 
argument is implied by associating his warrant 'here is the reason' with two embodied actions: pointing at the handout and showing it to Amor (line 5). After two opposing positions have been sequentially established, Hasan, overlapping with Rohan, launches an inclusive disagreement (Waring, 2001) addressing it to Amor with a gaze and shows a possibility that they can mention the explicit reason 'sister's marriage' (line 6). Hasan's affiliative action to Rohan's stance functions as a formation of peer alliance at this moment. Note that Hasan's gaze at this point is projected toward Amor, possibly as an indication of opposition to her previous claim. The fourth member $\mathrm{Hu}$ also demonstrably orients to the ongoing development of disagreement sequences between Amor and Rohan, and displays an alignment with Rohan's position with his repeated use of the word 'need' jointly reinforced by embodied actions of gaze and pointing (lines 8-11). After getting support from his peers, Hasan, overlapping with $\mathrm{Hu}$, reiterates his stance in line 12. Rohan also acknowledges Hasan's support in an attempt to make Amor accept their proposed text. Hu continues to support Rohan arguing that it is necessary to mention the specific reason (lines 14-17).

Amor, instead of accepting the views of the other three members, repeats her position implying that mentioning 'personal or family reason' is enough (line 18). Her recycling of the stance challenges the position of the opposite alliance. This is, however, immediately contested by the other two members, Hasan and Rohan, by invoking more authoritative handout guidelines again (lines 19-22). Hasan, building into a more conventional mitigating device of partial agreement, hints of an unfolding move that contrasts with Amor. He does so by making an irrelevancy claim (Muntigl \& Turnbull, 1998) of Amor's proposed text, commenting 'whether it is reasonable to mention' (line 22). Rohan also redraws her attention to the guidelines. Amor, however, only makes a minimal response with a softened acknowledgement token 'yeah'. She 
refrains from making further contribution and thus fails to challenge other members and defend her own position (line 24). Though Amor has not given up her position in order to align with her group members, she is displaying a sign of her further non-involvement at the moment. Inability to take a turn in order to defend one's one position is a sign of submission in argument frames (Kotthoff, 1993).

Amor's lack of further uptake gives Rohan an opportunity to launch another attempt to recycle his position that he again warrants with his embodied action (25-28). This is supported by his allies Hasan and $\mathrm{Hu}$ in line 26 and 29 with acknowledgements. In addition, Rohan's projected utterance in line 27 and 28 is co-constructed with an overlap by $\mathrm{Hu}$ in line 30 . Such a collaborative turn sequence (Lerner, 2004) is an example of affiliation between two members who hold the same stance. Following Lerner (ibid.), even when the turn is completed by the next speaker, the original speaker, Rohan in this context, maintains the authority over the turn's construction.

In these disagreement sequences due to oppositional stance taking practices, Rohan and Amor are interactionally constructed as the principal members who show opposite positions regarding whether to mention sister's wedding in the email specifically or not. Hasan and Hu are the aligning members for Rohan. From lines 24 to 32, three participants without an involvement of Amor co-construct the email, still inviting her with a gaze by $\mathrm{Hu}$ to accept as well as to contribute to the ongoing e-mail discourse. This makes Amor finally give up her stance and accept the opposite view by using the token 'okay' (line 35). It is noticeable that this is marked by some prosodic features: there is a noticeable delay in her acceptance indicated by a 0.2 pause and she pronounces the 'okay' token with a relatively weakened voice prefaced with a hedging device 'um'. Thus, giving up a position for concession is uttered in a hesitant manner (Kotthoff, 
1993: 213) making the action dispreferred. This, nevertheless, acts as a close of the disagreement sequence and paves the way for the participants to move to the next step in the task.

As we have seen above, when a possible conflict develops and progress with the ongoing task comes to a halt due to the lack of consensus between two or more members of the group, alliance formation with a particular group member(s) is visible in the interaction. Participants achieve alliances not only through their talk but also through nonvocal resources such as gaze and gesture. The practice of alliance formation here is comparable to the similar feature 'building alliances' in Kangasharju's (2002) data from meeting talks. The participants in his data used alliances as devices to gain interactional power in decision making stage to reach to institutional goal of the meeting (p. 1460) (cf. Mori, 2003). In the present context, teams are formed based on the participants' shared interpretation of the task description in the handout. Rohan, Hu and Hasan frequently use the handout as a warrant for their arguments. Alliance in teams and referring to the handout as a source of authority are two effective resources by which the participants accomplish this peer activity.

The previous excerpt also presents a case where a pedagogical task is interpreted differently by different students. The major source of tension among the participants is their different views on whether they need to provide a specific reason for an email request. Such multiple interpretations of language learning tasks have been reported in previous studies in second language pedagogy. Kumaravadivelu (2003), for example, argues that different students can understand the tasks differently, and as a result there can be differences between teacher intentions and learner interpretations of the tasks (also see Breen, 1989). The source of disagreement in the present data set is similar to Kumaravadivelu's concept of 'procedural mismatch', the "locally specified, currently identified, bottom up tactics" (p. 87) employed by 
the students to interpret and execute the task. Learning outcomes are the result of a fairly unpredictable interaction between the student, the task, and the task situation (ibid.).

\section{Proposing alternative position and conceding}

There are fewer positions than the number of participants in a multiparty discussion. Excerpt 8 , however, presents the only case in the collection when three members hold three different positions before a fourth member in the group Hasan proposes an alternative position that is consequential to closing the episode. The participants are collaboratively discussing the appropriate text for the closing of the e-mail. The emerging point of disagreement here is Rohan's opposite view on Hu's idea of using the word 'appreciate' to the Director.

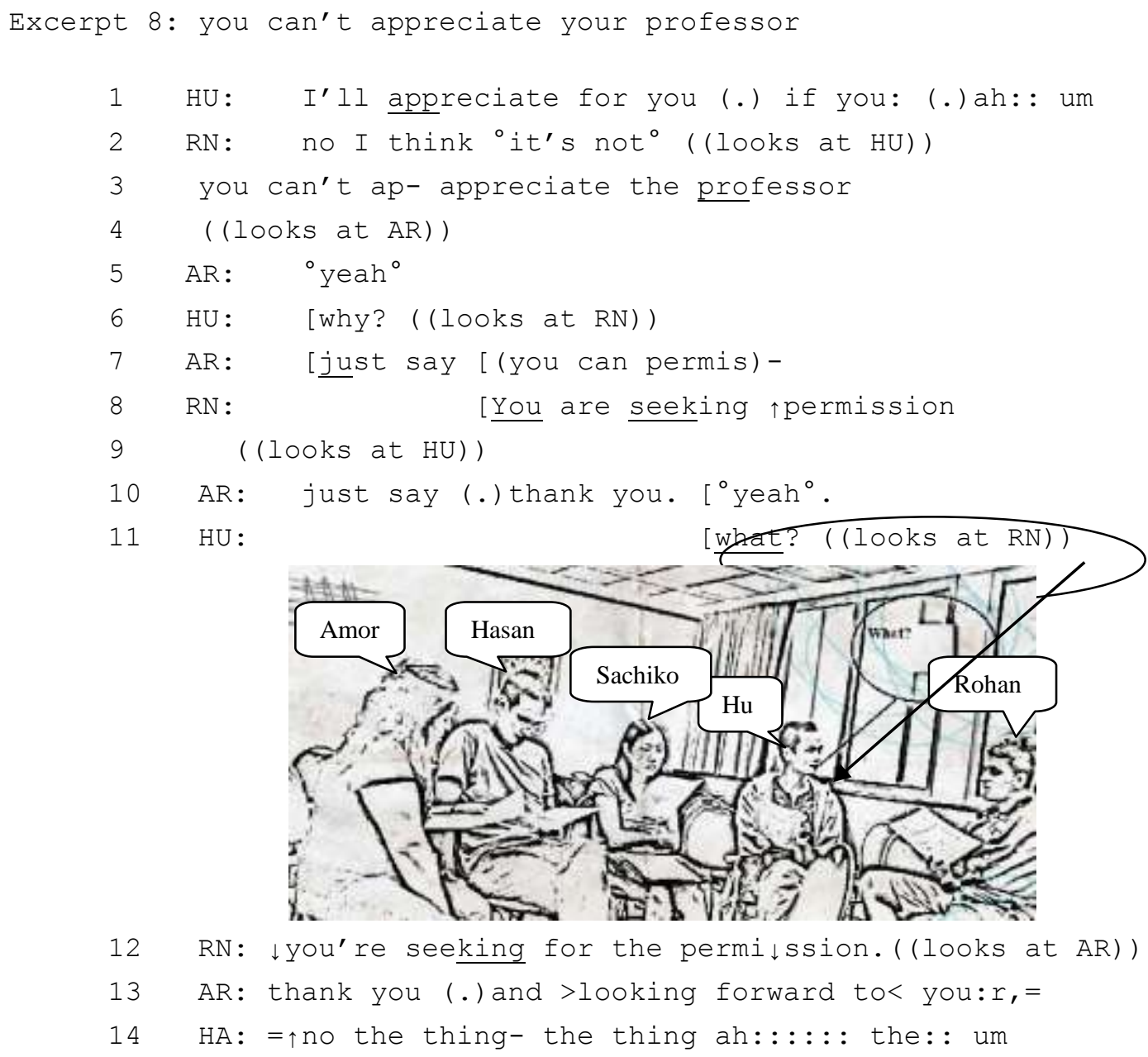

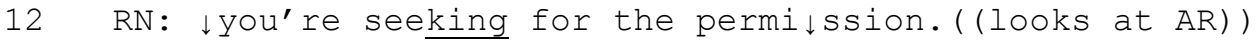

13 AR: thank you (.) and >looking forward to< you:r, =

14 HA: = no the thing- the thing ah: : : : : the: : um 


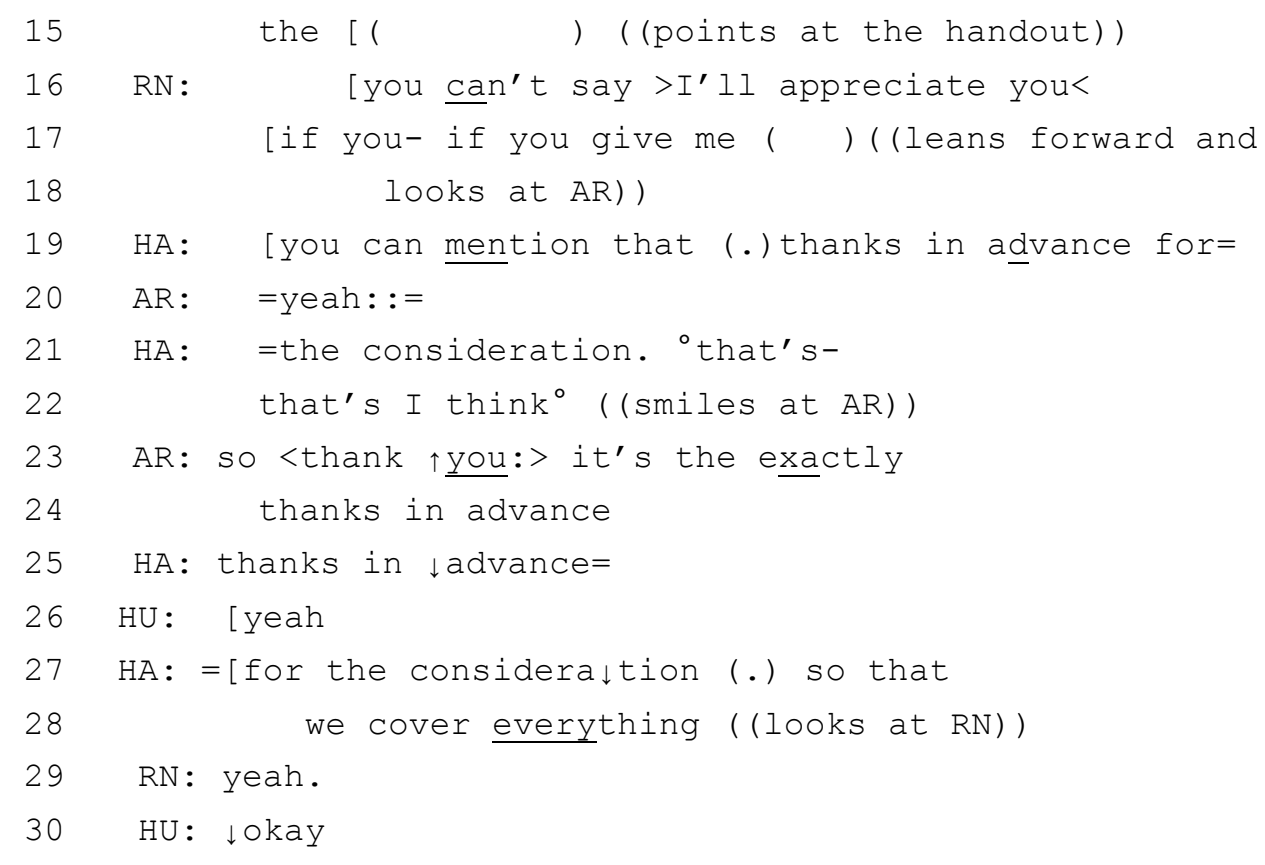

In line $1, \mathrm{Hu}$ proposes the closing of the e-mail text beginning with the fragment 'I'll appreciate for you (.) if you'. Her turn remains incomplete and ends with perturbations (micropauses, lengthenings, and 'ah::' and 'um' tokens) showing that Hu has trouble continuing composing the text. This implies that he is inviting his interlocutors for a further contribution to complete the ongoing piece of discourse. Rohan prepares to disalign with $\mathrm{Hu}$ using a dispreferred and later aborted response 'no I think it's not' with accompanying gaze to Hu. It is ambiguous at this point what further comment he was going to make. Then he treats Hu's proposed text 'to appreciate the professor' as inappropriate by implicitly constructing a power hierarchy between the students and the professors, implying that such power distance is to be maintained in composing the email. By doing this he treats his recipient as having insufficient knowledge of e-mail pragmatics. Rohan's position rests on his argument when he is interchangeably using two different reference terms, 'professor' and 'Director' (line 3), to mean that writing an e-mail to the Director is not different from writing an e-mail to a professor in terms of the higher position they hold vis-à-vis students. Rohan's argument ends with his appeal with a gaze to ask for support to Amor to 
accept his stance (lines 3-4). Amor shows a weak agreement with Rohan (line 5) and makes an attempt to mitigate the developing disagreement between Rohan and Hu by proposing an alternative text in line 7, which she aborts when she overlaps with Rohan in line 8.

$\mathrm{Hu}$, however, does not admit that his email text is inappropriate; instead he challenges Rohan by asking for a more explicit account (line 6). In addition to the immediate action of requesting an explanation, Hu's use of the question word 'why' sets up an opposition between Hu's and RN's stance (Tagaki, 1999) on whether or not a professor can be "appreciated". A response to a why question will have to include an account when the previous utterance is marked as unsatisfactory in some way (Antaki, 1994). The question, thus, creates a condition for Rohan to provide an account in order to defend his position because in such an argument the party who cannot answer the opponent's questions is likely to lose the case (M. Goodwin, 1990; Fujimoto, 2010). Here again in line 8, Rohan attempts to legitimize his knowledge by arguing that because they are seeking permission it is not appropriate to write 'I'll appreciate' to the email recipient. Rohan is again invoking professor as the authority for whom 'I'll appreciate' is not appropriate. Another point notable at this moment is that although $\mathrm{Hu}$ is continuously challenging Rohan with questions, he does not provide further accounts for the appropriateness of this email text, nor does he provide counter arguments to prove Rohan wrong. Hu's absence to use account as a resource to establish the plausibility of his argument might be a potential cause to lead him toward a failure for establishing his position as a valid one. Ideas on rhetorical analysis provides some valid basis for this-- accounts help to counter alternatives as well as resist being countered in the argumentative organization of discourse (Potter, 1996)

When there are no signs of a consensus in sight, Amor makes a second attempt to bring this disagreement sequence to a close by uptaking the previously aborted text with 'just 
say thank you' (line 10). She does not provide any account for this but is demonstrably oriented to resolve the disagreement. Her main concern is visibly to get the email written. Hu is not convinced by Rohan's explanation, nor does he orient to Amor's alternative text and orientation to get the writing task done. He further pursues a point of opposition by posing another challenge question 'what?' with a louder pitch (line 11). Rohan's repetition of his stance in line 12 marks that the disagreement is more aggravated (M. Goodwin, 1990). Meanwhile, Amor makes a third attempt to close the disagreement between two principal opposing members by proposing her own version of the closing part of the email (line 13).

Amor's attempt proves futile when another member of the group Hasan, whose participation was minimal until now, launches disagreement with what is going on at the moment (line 14). Using the footing of the animator (Goffman, 1981), he draws the group members' attention to the handout as a point of reference. Rather than orienting to the new developments in the sequence, Rohan, however, recycles his own position arguing that 'I'll appreciate you' is not appropriate for the e-mail text. He then initiates to propose another alternative text 'if you give me' for the email (line 17).

Line 20 is an important moment here. Hasan does not align with any of the alternatives proposed so far, but goes on to propose another text-- 'thanks in advance for the consideration'-as more appropriate alternative for the e-mail (lines 19 and 21). This interactional property of proposing an alternative text makes the episode of particular interest in the collection and also identifies the sequence different from the examples of 'peer alliance'. This proposal is promptly agreed by Amor with a turn-initial conclusive marker 'so' and a repetition followed by a selfrepair (Schegloff et al., 1977) in line 25. Following Schiffrin (1987), the use of discourse marker 'so' also functions as a hint of concluding an argument sequence. In terms of participation 
framework (Goffman, 1981), Amor makes a strategic move here from the footing of principal to the footing of animator echoing Hasan's voice. Such a sudden position shift is concessionindicative and can also be face-threatening (Kotthoff, 1993) because Amor is giving up a position that she has been arguing for. Amor's sudden conceding of her stance paves a path for Hasan to further legitimize the appropriateness of his text with an account formulating an extreme case (Pomerantz, 1986)-- 'so that it covers everything' (line 28). That 'everything' is addressed in the handout also hints a candidate pre-closing of the sequence (Garfinkel \& Sacks, 1970) in this context. On hearing this, Rohan, one of the principal disagreeing members, gives up his position and accepts Hasan's proposal without any further question (line 29). Hu, another principal member, also aligns with Hasan with the acknowledgement and acceptance token 'okay' (Schegloff, 2007). Hasan interactionally assumes the role of a mediator bringing two or more disagreeing parties to a consensus. His mediation role, however, differs from what has been conventionally assigned in dispute mediation contexts where the mediator is supposed to work as a third party neutral (Jacobs, 2002). Also of particular interest at this point is the consensus they build before closing the sequence. This practice shows some similarity with Jefferson's (1984) observation in trouble telling situations where the display of "interactional cohesiveness is a general technique for the management of topic rupture" (p.194). This observation is corroborated by the peer group activities, in which the party whose position is being established displays convincing arguments.

\section{Discussion and Conclusion}

The detailed analysis of the video data focused on the stepwise exit from disagreement, and the interactional and material resources through which the participants accomplish these exits. I discussed three sequential patterns of a particular type of exit- conceding- to characterize an 
array of actions that participant(s) deploy to give in to the stance held by another member(s). In the first pattern, analysis showed that when the members have an exchange of disagreement, one of the members conceded to another member when a claim of understanding was made by reading from a source text or by referring to the handout guidelines (excerpts 4 and 5 respectively). Analysis of the data also showed that peer alliance among members who hold the same stance is consequential for an opponent member's giving in to the pervading position (excerpts 6 and 7). The third type of conceding was accomplished when one of the members provided an alternative position to the already established three opposing stances (excerpt 8). Whenever disagreements emerged either in group discussions or in collaborative writing tasks, these were locally managed by the participants themselves. In all segments in the data presented above, all disagreements ended up with a position acceptable to all the members. This shows that group works are the sites where students develop both academic as well as social skills (Leki, 2002).

Because disagreements in the data corpus are frequent and unmitigated, they are expected and preferred pedagogical practices in language classrooms. These disagreements have positive consequences by creating opportunities for the group members to display their stances, to agree or disagree with each other's views and to get the discussion or writing task done. Findings from this study also make some connection with Kotthoff's (2002) observation in closing of dispute talks. In cases where one party had to give in to another disagreeing party, the conceding was uttered in a hesitant matter in a stepwise fashion. This implies that giving up a position that has already been argued for indicates a dispreferred action and "can be face threatening" (p. 213). For example, in excerpt 4, Amor conceded with a hesitant marker 'um::' (line 14); in excerpt 5, Amor makes an attempted account (line 15) before she gives in; in excerpt 6, Rohan invokes 
uncertainty to save his face before conceding (lines 39, 40); in excerpt 7, Amor displays silence and hesitation (lines 32,34); and finally in except 8 , none of the primary disputing members concedes to another member unless a third member in the group proposes another alternative. Vuchinich (1990) notes that studying such closing patterns of conflict or disagreement talk provides a rich site of trajectories where submission and dominance are constantly at play. Though the objective of the present study is not to focus on the interplay of dominance and submission, I argue that disagreement and argument episodes are a rich site to further explore power at play in situ. Resources like understanding claim, peer alliance or alternative position provide interactional power to the participants to legitimize their positions through interactional dominance.

This study also expands our understanding of the intricate maneuvers involved in group works in university classes in general and writing classes in particular. Rather than simple teacher observations or student-reported opinions regarding how group works function, analysis of micro-details allows us to see how the participants draw multiple resources through their talk and embodied actions to do collaboration and co-construct meaning. Frazier (2007) convincingly argues that studying group interaction is rewarding for language learning and teaching purposes because "something quite profound is happening inside the interactions of writing students during group work" (p. 207).

Some interactional features observed in the collaborative writings bear similarities with Keys' (1996) findings from analyzing student social interactions while writing collaborative lab reports in a ninth grade science class. For example, while investigating how collaborative peer discussions provided cognitive support for writing laboratory reports, she found that students frequently used peer teaching strategy "either directly imparting information, or facilitating 
learning for his or her partner" (p. 182). Haller et al. (2000) also observed a similar interactional feature among sophomores while they were collaboratively solving their engineering problems in groups. Their findings show interesting dynamics of peer interaction that result from asymmetrical distribution of knowledge and technical expertise in the group. Keppler and Luckmann (1991) recognize such sequential properties as 'interactional teaching sequences'. In the present context as well, group members assumed the role of 'doing being-a teacher' at moments of disagreements. For example, this is more visible in excerpt 8 where Yuki and $\mathrm{Hu}$ make continuous attempts to explain the task from the handout to Rohan by paraphrasing it several times. In order to further expand our understanding, it will also be useful to study how students in academic English class orient to and develop their writing skills building on academic discussions that are embedded in different phases of collaborative writing and how their display of differing stances relates to their development of writing. 


\section{References}

Antaki, C. (1994). Explaining and arguing: The social organization of accounts. London: Sage.

Brown, P. \& Levinson, S. C. (1987). Politeness: Some universals in language usage. Cambridge: Cambridge University Press.

Dersley, I. \& Wooton, A. J. (2001). In the heat of sequence: Interactional features preceding walkouts from argumentative talk. Language in Society, 30, 611-636.

Arminen, I. (2005). Institutional interaction: Studies of talk at work. Aldershot, England: Ashgate Publishing.

Bonito, J. A. \& Sanders, R. E. (2002). Speakers' footing in a collaborative writing task: A resource for addressing disagreement while avoiding conflict. Research on Language and Social Interaction, 35, 481-514.

Boyd, E. \& Heritage, J. (2006). Taking the history: Questioning during comprehensive history-taking. In J. Heritage \& D. W. Maynard (Eds.), Communication in medical care: Interaction between primary care physicians and patients (pp. 151-184). Cambridge: Cambridge University Press.

Breen, M. (1989). The evaluation cycle for language learning tasks. In R. K. Johnson (Ed.), The second language curriculum (pp. 187-206). Cambridge. Cambridge University Press.

Carroll, D. (2005). Co-constructing competence: Turn construction and repair in novice-tonovice second language interaction. Unpublished doctoral dissertation, University of York, York, England.

Drew, P. \& Heritage, J. (1992). Analyzing talk at work: an introduction. In P. Drew \& J. Heritage (Eds.), Talk at work: Interaction in institutional settings (pp. 3-65). Cambridge: Cambridge University Press.

Davidson, J. (1984). Subsequent versions of invitations, offers, requests, and proposals dealing with potential or actual rejection. In J.M. Atkinson \& J. Heritage (Eds.), Structures of social action (pp. 102-128). Cambridge: Cambridge University Press.

Drew, P. (1991). Asymmetries of knowledge in conversational interactions. In I. Markovà, \& K. Foppa (Eds.), Asymmetries in dialogue (pp. 29-48). Hemel Hempstead: Harvester Whetsheaf.

Frazier, S. (2007). Tellings of remembrances 'touched off' by student reports in group work in undergraduate writing classes. Applied Linguistics, 28, 189-210. 
Fujimoto (2010). Agreements and disagreements: The small group discussion in a foreign language classroom. In G. Kasper, H. t. Nguyen, D. R. Yoshimi, \& J. K. Yoshioka (Eds.), Pragmatics and language learning, vol. 12 (pp. 297-325). Honolulu: University of Hawai'i, National Foreign language Research Center.

Gardner, R. ( 2004). On delaying the answer: Question sequences extended after the question. In R. Gardner \& J. Wagner (Eds.), Second language conversations (pp. 246-266). London: Continuum.

Garfinkel, H. \& Sacks, H. (1970). On formal structures of practical actions. In J. C. McKinney \& E. A. Tiryakian (Eds.), Theoretical sociology (pp. 337-366). New York: Appleton Century-Crofts.

Georgakopoulou, A. (2001). Arguing about the future: On indirect disagreements in conversations. Journal of Pragmatics, 33, 1881-1900.

Goffman, E. (1981). Forms of talk. Philadelphia: University of Pennsylvania Press.

Goodwin, C. (1981). Conversational organization: Interaction between speakers and hearers. New York: Academic Press.

Goodwin, M. H. (1990). He-said-she-said: Talk as social organization among Black children. Bloomington: Indiana University Press.

Greatbatch, D. \& Dingwall, R. (1997). Argumentative talk in divorce mediation sessions. American Sociological Review, 62, 151-170.

Haller, C. R., Gallagher, V. J., Weldon, T. L, \& Felder, R. M. (2000). Dynamics of peer education in cooperative learning workgroups. Journal of Engineering Education, 89, 285293.

Have, P. t. (2007). Doing conversation analysis. $2^{\text {nd }}$ edition. London: Sage.

Hellermann, J., \& Cole, E. (2008). Practices for social interaction in the language-learning classroom: Disengagements from dyadic task interaction, Applied Linguistics, 30, 186215.

Heritage, J. (1984). A change-of-state token and aspects of its sequential placement. In M. Atkinson \& J. Heritage (Eds.), Structures of social action: Studies in conversation analysis (pp. 57-101). Cambridge: Cambridge University Press.

Heritage, J. (1988). Explanations as accounts: A conversation-analytic approach. In C. Antaki (Ed.), Analyzing everyday explanation (pp. 127-144). London: Sage. 
Heritage, J. C. \& Watson, R. (1979). Formulations as conversational objects. In G. Psathas (Ed.), Everyday language: Studies in ethnomethodology (pp. 123-162). New York: Irvington.

Holt, E. (2010). The last laugh: Shared laughter and topic termination. Journal of Pragmatics, 42, $1513-1525$.

Jacobs, S. (2002). Maintaining neutrality in dispute mediation: Managing disagreement while managing not to disagree. Journal of Pragmatics, 34, 1403-1426.

Jefferson, G. (1984). On step-wise transition from talk about a trouble to inappropriately next-positioned matters. In J. M. Atkinson \& J. C. Heritage (Eds.), Structures of social action (pp. 191-222). Cambridge: Cambridge University Press.

Jefferson, G. (1979). A technique for inviting laughter and its subsequent acceptance declination. In G. Psathas (Ed.), Everyday Language: Studies in ethnomethodology (pp. 79-96). New York: Irvington Publishers Inc.

Kangasharju, H. (2002). Alignment in disagreement: forming oppositional alliances in committee meetings. Journal of Pragmatics, 34, 1447-1471.

Kasper, G., \& Ross, S. J. (2007). Multiple questions in oral proficiency interviews. Journal of Pragmatics, 39, 2045-2070.

Keppler, A. \& Luckmann, T. (1991). 'Teaching': Conversational transmission of knowledge. In I. Markovà \& K. Foppa (Eds.), Asymmetries in dialogue (pp. 143-165). Hemel Hempstead: Harvester Whetsheaf.

Keys, C. W. (1996). Writing collaborative laboratory reports in ninth grade science: Three case studies of social interactions. School Science and Mathematics, 96, 178-186.

Kotthoff, H. (1993). Disagreement and concession in disputes: On the context sensitivity of preference structures. Language in Society, 22, 193-216.

Kumaravadivelu, B. (2003). Beyond methods: Macrostrategies for language teaching. New Haven: Yale University Press.

Leki, I. (2001). 'A narrow thinking system': Non-native English speaking students in group work projects across the curriculum. TESOL Quarterly, 35, 39-67.

Lerner, G. (2004). Collaborative turn sequences. In G. Lerner (Ed.) Conversation analysis: Studies from the first generation (pp. 225-256). Amsterdam: John Benjamins.

Levinson, S. C. (1983). Pragmatics. Cambridge: Cambridge University Press. 
Mori, J. (1999). 'Well I may be exaggerating but' ...: Self-qualifying clauses in negotiation of opinions among Japanese speakers. Human Studies, 22, 447-73.

Mori, J. (2003). The construction of interculturality: A study of initial encounters between Japanese and American students. Research on Language and Social Interaction, 36, 143-84.

Muntigl, P. \& Turnbull, W. (1998). Conversational structure and facework in arguing. Journal of Pragmatics, 29, 3, 225.

Pomerantz, A. (1984). Agreeing and disagreeing with assessments: some features of preferred/dispreferred turn shapes. In J. M. Atkinson \& J. Heritage (Eds.), Structures of social action: Studies in conversation analysis (pp.57-101).Cambridge: Cambridge University Press.

Pomerantz, A. (1986). Extreme case formulations: A way of legitimizing claims. Human Studies, 9, 219-229.

Pomerantz, A. (1988). Offering a candidate answer: An information seeking strategy. Communication Monographs, 55, 360-73.

Potter, J. (1996). Representing reality: Discourse, rhetoric and social construction. London: Sage.

Sacks, H., Schegloff, E. A., \& Jefferson, G. (1974). A simplest systematics of turn-taking for conversation. Language, 50, 696-735.

Schegloff, E. A. (2007). Sequence organization in interaction: A primer in conversation analysis. Cambridge: Cambridge University Press.

Schegloff, E. (2005). On dispensability. Research on Language and Social Interaction, 37, 95149.

Schegloff, E. A., Jefferson, G., \& Sacks, H. (1977). The preference for self-correction in the organization of repair in conversation. Language, 53, 361-382.

Schiffrin, D. (1987). Discourse markers. Cambridge: Cambridge University Press.

Simmel, G. (1950). The sociology of Georg Simmel. Translation and with an introduction by K. H. Wolff. Grencoe: The Free Press.

Stokoe, E. H. (2000). Constructing topicality in university students' small group discussion: A conversation analytic approach. Language and Education, 14, 184-203.

Storch, N. (2005). Collaborative writing: Product, process, and students' reflections. Journal of Second Language Writing, 14, 153-173. 
Swain, M., \& Lapkin, S. (1995). Problems in output and the cognitive processes they generate: A step towards second language learning. Applied Linguistics, 16, 371-391.

Takagi, T. (1999). 'Questions' in argument sequences in Japanese. Human Studies, 22, 397-423.

Vuchinich, S. (1990). The sequential organization of closing in verbal family conflict. In A.

Grimshaw (Ed.), Conflict talk: Sociolinguistic investigations of arguments in conversations (pp. 118-139). Cambridge: Cambridge University Press.

Waring, H. Z. (2001). Balancing the competing interests in seminar discussion: Peer referencing and asserting vulnerability. Issues in Applied Linguistics, 12, 29-50.

Waring, H. Z. (2005). Peer tutoring in a graduate writing center: Identity, expertise and advice resisting. Applied Linguistics, 26, 141-168.

Warschauer, M. (2002). Networking into academic discourse. Journal of English for Academic Purposes, 1, 45-58. 


\section{Appendix: Transcription Symbols}

[

$=$

(.)

word

:

-- $\quad$ A dash indicates a cut-off.

$?$

•

$\downarrow \uparrow$

WORD

${ }^{\circ}$ word $^{\circ}$

<word >

$>$ word $<$

(word)

( )

$((\quad))$ talk.
A single bracket on the left indicates the point of overlap onset. Equal signs indicates latching — no gap between two lines. The number in brackets indicates a time gap in tenth of a second. A dot in parenthesis indicates a tiny gap within or between utterances. An underlined part indicates stress or speaker emphasis.

Colon indicates prolongation of the immediate prior sound. Multiple colons indicate a more prolonged sound.

A question indicates rising intonation.

A period indicates a stopping fall in tone.

A comma indicates a continuing intonation.

Arrows indicate marked shifts into higher or lower pitch in the utterance-part immediately following the arrow.

Upper case indicates loud sounds relative to the surrounding talk.

Fragments bracketed by degree signs are relatively quieter than the surrounding

right/left carets bracketing a fragment indicate that the bracketed talk is noticeably slower than the surrounding talk.

left/right carets bracketing a fragment indicate that the bracketed talk is noticeably faster than he surrounding talk.

Parenthesized words are especially dubious hearings or speaker identifications. Empty parentheses indicate the transcriber's inability to hear what was said. A description enclosed in double parentheses indicates a non-verbal activity.

(Transcription developed by Gail Jefferson, adapted from ten Have, 2007). 